\title{
OLFACTORY REACTIONS IN AMPHIBIANS
}

\section{JONATHAN RISSER}

ONE FIGURE

\section{CONTENTS}



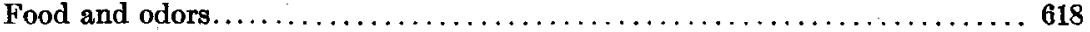

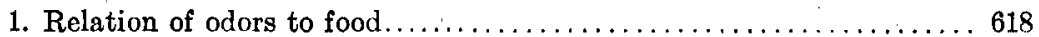



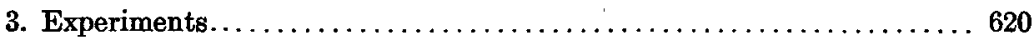

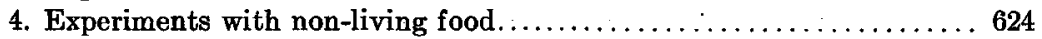

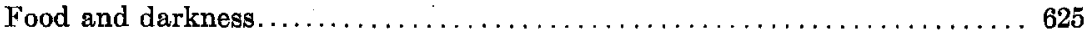

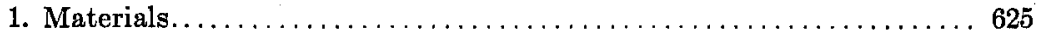

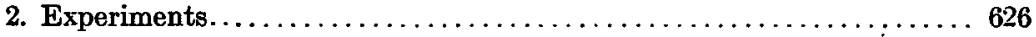

3. Abnormal odors and darkness. . . . . . . . . . . . . . . . . 627

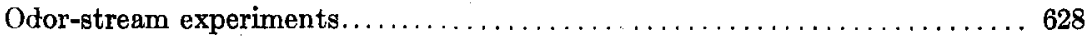

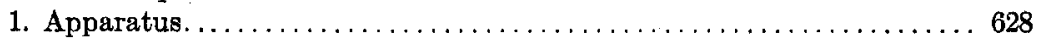

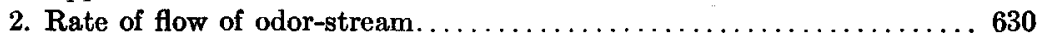

3. Methods.................................... 630

4. Substances used in the tests........................ 631

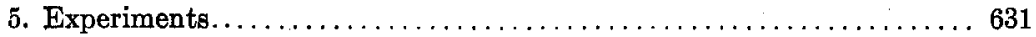

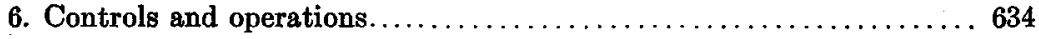

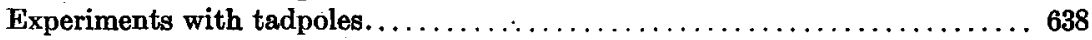

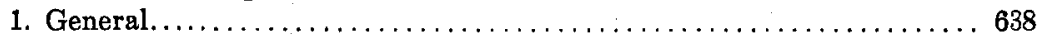



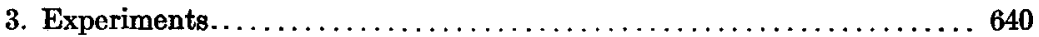



b. Second set of tadpoles........................ 641

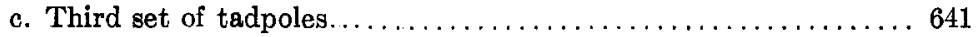

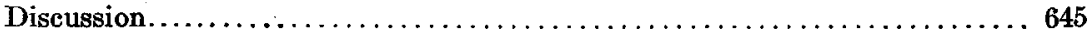

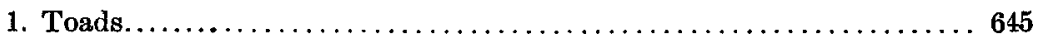

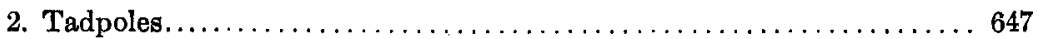

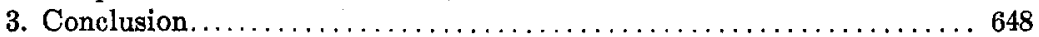

Summary...................................... 649

Bibliography $\ldots \ldots \ldots \ldots \ldots \ldots \ldots \ldots \ldots \ldots \ldots \ldots \ldots \ldots \ldots \ldots \ldots \ldots \ldots \ldots \ldots \ldots$ 


\section{INTRODUC'TION}

It is the purpose of this paper to record some observations and experiments on the olfactory reactions in certain amphibians, more especially in the toad (Bufo americanus LeConte). Initial experiments were tried on frogs (Rana virescens and R. catesbiana), both larval and adult, but the work did not prove promising and was therefore given up.

These investigations were undertaken at the suggestion of Dr. G. H. Parker of the Zoölogical Laboratory of Harvard College and to him for his kindly interest and helpful advice I wish to express my deepest appreciation.

\section{FOOD AND ODORS}

\section{Relation of odors to food}

There is little evidence that the relation of odors to food has been taken into account in any investigation of the habits of the different amphibians. In the quantitative studies of the stomach contents of frogs and toads no evidence has been found to show that certain foods are preferred by these animals. Fischer-Sigwart ('97) believed that frogs and toads were indiscriminate feeders. Needham ('05) has shown the food of the bullfrog (R. catesbiana) to be extremely varied. Lockwood ('83) in speaking of the toad, says "I do not believe it can smell. It catches insects, but only when such probable food is in motion." Knauer ('75), however, mentions cases where decomposing animal food was rejected by toads after having been taken into the mouth. Schaeffer ('11) found that certain caterpillars were refused by frogs in a similar manner. In both cases other factors may have been of disturbing influence. Hartman ('06) found no special preponderance of one species over another in the insects taken from the stomach of toads collected at random. Garman ('92) has records of the food of toads from which one might conclude that ants were more sought after than other insects. Such a condition, however, may have been due to the fact that younger newly metamorphosed toads being close to the ground met ants more frequently than they did 
other insects. Hodge ('98) refers to the large numbers of houseflies eaten by the toad. Schaeffer ('11) mentions the variety of insect food taken by frogs in confinement. Quaintance and Brues ('05) show how toads make use of very diverse forms of insects as food. Slonaker ('00) and others have fed meat to toads, by simulating the motion of small insects to attract attention. The behavior of toads and frogs in confinement leads to the inference that food ordinarily must be in a living condition and in motion to be attractive.

Among food materials taken by the toad under normal circumstances there are many insects with characteristic odors. Conradi ('01) infers that the odor of the cucumber beetle (Anasa tristis) is inimical to the toad, but Hill ('73) observed no disastrous results to toads that had fed on this insect. Neither frogs nor toads hesitate to make use of other vertebrates as food, when occasion offers, or to devour members of their own species. Can it be shown that these animals are stimulated to seek for food or refuse it because of odors? With this question in mind the following feeding experiments were carried on with the toad (Bufo americanus LeConte):

\section{Materials and methods}

The toads used in these experiments were obtained in the vicinity of Cambridge, Massachusetts, quite late in the year. They were kept in a large box containing soil and leafmold in a moderately cool basement room. The soil was kept damp and the box dark. Some of the animals buried themselves in the soil, others took shelter under bits of wood. The animals reacted normally in all respects, taking food when offered. The food consisted mainly of mealworm larvae (Tenebrio molitor), of earthworms and dungworms (Allolobophora foetida), flies and other insects. Some of the toads were removed to large jars for greater convenience. Not all the animals were alike, some showing a greater tendency to hibernate than others. Food was generally given the toads at intervals of several days, but this procedure was modified as necessary. For convenience the experiments were carried on with the 
toads confined in a large metal pan. In this way the animals were kept within bounds but were still allowed much freedom of movement.

\section{Experiments}

The first experiment was made to determine whether choice was made between two forms of food with specific odors. Previous to the trials earthworms had been fed freely to the toads, and it might be supposed that because of the peculiar odor of the dungworm, the latter would be refused as food.

Toads No. 1 and No. 2 were in the box in which the experiments were conducted before the dungworms were introduced. Toad No. 1 saw the worms soon after they had begun to crawl. It quickly hopped toward the worms and attempted to snap up the nearest worm. The attempt was unsuccessful and the lips were wiped with the forefeet. Sandgrains on the lips evidently produced a mechanical stimulus which was followed by the wiping.

The dungworms were then freed of all the adhering sand and again placed in the center of the box. Although the movement of the worms was sufficient to attract the toads, no further attempt was made to take the worms. When a mealworm larva was put in with the dungworms, it was quickly snapped up by the nearer toad, No. 1.

Dividing a dungworm then into a number of pieces, these were placed in a shallow vessel before the toads. Into the vessel there were also dropped two mealworm larvae. From the mass of wriggling pieces one of the mealworms was immediately selected and swallowed. Upon the dorsal surface of the other mealworm a drop of oil of pennyroyal was now placed; the mealworm with the oil was also quickly taken. Toad No. 2 made several unsuccessful attempts to take the remaining dungworm, but abandoned the dungworm, taking later some mealworms that had been put in the box. Similar trials with two other toads gave like results, leading to the conclusion that the dungworm is not used as food under normal condition, a conclusion that was subsequently shown to be false. 
Some days later, the same toads, Nos. 1 and 2, were again tested with the dungworms. Three worms of medium size placed in the center of the box were immediately noticed by Toad No. 1 . No attempts to take any worms followed. The odor characteristic of the worms was evident and the cutaneous exudate was visible. A mealworm dropped into the vessel among the dungworms quickly became covered with the slime of the worms. That the mealworm was recognized as a new object by the toad, is proven by the actions of the toad. The attitude peculiar to the animals when watching some object, was immediately assumed. As soon as the mealworm had crept away from the dungworms, the toad snapped it up. Another mealworm dropped into a dish containing some fragments of dungworm was watched by the toad as long as it moved. After it ceased moving it was of no more interest to the toad. No attention was paid to the fragments of dungworm although they were wriggling. A second mealworm smeared with the exudate from the earthworm was quickly snapped up by No. 1. This reaction was followed by the wiping of the lips with the forefeet; whether this was done to remove the slime adhering to the lips was not determined. The wiping action again took place when the same toad took another mealworm similarly prepared. Toad No. 2 exhibited the same reactions under similar conditions.

A series of trials with the different toads proved that fragmented dungworms were never taken, even though they exhibited decided movements. The trials also showed that the toads preferred the mealworms, and that the odor of the dungworms when applied to the mealworms was not deterrent to the toads.

Trials carried out with the same toads, to determine their preference for mealworms over earthworms, indicated that the mealworms were the more desired form of food. These were selected from among the earthworms. It is not clear why this should have been so; previously and later in the course of the experiments both earthworms and mealworms were taken promiscuously. 
In a subsequent trial with Toad No. 1 mealworms placed among dungworms were taken after they had moved away from the dungworms. Broken pieces of dungworm taken into the mouth were followed by the wiping action. The exudate alone did not affect the toad in a similar manner. Although the odor was evident on mealworms smeared with the exudate, this did not hinder them from being taken, the only effect being a peculiar 'gaping' action after the mealworm had been swallowed.

To determine whether the color of the mealworm was a deciding factor, attempts to approximate the color of earthworms and dungworms were made. Mealworms tinted to resemble the color of the earthworms were taken without hesitancy. Such mealworms were always taken from among fragments of dungworms and earthworms.

In some trials' for determining the effect of distinctly abnormal odors and natural foods, the following observations were recorded.

The toads experimented upon were No. 3, which was very responsive, and No. 4, which was sluggish. Dungworms were put in the experimental cage in a Petri dish. They attracted the attention of Toad No. 3, but otherwise it did not respond. The dungworms were then cut up and again placed in the cage, but again the toads did not react. Mealworms were now substituted for the dungworms and No. 3 immediately took two of these. Oil of pennyroyal was put on certain mealworms and when these were introduced, two,were taken by Toad No. 3 . No discomfort was shown by the toad. Fragments of dungworms were placed in the cage, but were not taken by the toads. Mealworms covered with dungworm juice were quickly taken, and accidentally one piece of a dungworm was taken and swallowed; another piece was brushed from the mouth. The mouth was opened several times in succession as though the fragment of worm had been unpalatable.

Four days later the same toads took mealworms with the juice of dungworms, and the exudate smeared upon them. Both toads took mealworms smeared with oil of pennyroyal unhesitatingly. Again later, the same toad, No. 3, did not discrimi- 
nate between earthworms and dungworms. The latter were irritated in such a manner as to make the integumentary exudate distinctly noticeable. This was not deterrent in any case.

Whatever may have been the cause of the refusal of the dungworms in the earlier trials has not been made clear, for later trials showed no aversion to the dungworms on the part of the toads.

A series of trials with the toads, in which the conditions of feeding were carried to a degree far beyond what might be expected to occur at any time normally, showed that many odors were not repellent when associated with food.

To hungry toads was given the choice of taking mealworms with unknown odorous substances, and others without such substances. Ether, chloroform and alcohol could not be made use of, because of their fatal action on the mealworms. Clove oil, oil of cedar, oil of pennyroyal, oil of bergamot, oil of citronelle, aniline oil, carbon bisulphide and iodine in saturated solutions were made use of. In the experiments there often arose the question of a fatal dose. But none of the toads died during the trials. Several of the trial records are transcribed:

Toad No. 1. One mealworm eaten, after which two mealworms with oil of pennyroyal taken within one minute; only effect was 'gaping' several times. Rest for ten minutes, then mealworms put in a dish too high for toad to get into. Toad in attentive attitude, and again when offered took clean worms and also one with oil of cloves. Odor was not repellent, nor was any after-effect noticed.

Four days later the same toad ate three mealworms, two with clove oil and one with oil of citronelle.

Toad No. 3. Took in two successive trials, two clean mealworms, two with oil of pennyroyal and two with carbon bisulphide; and later two clean mealworms, two with aniline oil, and two with oil of rose geranium.

Toad No. 5. At one trial, took two mealworms with oil of pennyroyal and one earthworm with the same oil applied.

The oil of pennyroyal appeared to be more irritating to the lips of the toads than the other substances used; the wiping 
of the lips was the only reaction seen after the toad swallowed worms treated with this oil.

Iodine, when taken into the mouth with the larvae seemed to be more productive of discomfort than the oils did. The larvae were not refused at any time during the trials, nor were the substances deterrent because of the attendant odors.

\section{Experiments with non-living food}

Some experiments were made to determine whether animal food that gave no evidence of being alive would be taken by the toad. In the feeding trials previous, only mealworms in motion were used for food; no attempts to use inert worms were made. Pupae of the mealworms were offered the toads. When the pupae were first dropped into the cage, they often made spasmodic motions, but these soon ceased. Sometimes the toads took the pupae when thus in motion. Mealworm larvae, freshly killed and motionless, were never taken. By means of a delicate strand of silk threaded into a larvae, these could be dragged over the bottom of the cage in a manner to imitate partially the living condition. The toads could be induced to snap up such larvae, and when once in the mouth they were not rejected. Knauer ('75) gives instances of the rejection of decomposing earthworm. My experience was to the contrary. Bits of meat fashioned into semblance of mealworms when thus drawn past the toad, and taken into the mouth, were not rejected.

Dead flies also could be suspended and moved before the toads. These were attractive to the toad even if abnormally odorous. Artificial larvae were fed in a few instances to the toads. These were made from absorbent cotton and paraffine, and could be substituted for the living worms if set in motion by means of the thread.

Toad No. 1 swallowed two such false larvae in the course of one trial. These false larvar were smeared with oil of clove and iodine solution in different trials. 
In the presence of the living larvae, no attention was paid to motionless artificial larvae, but if these were set in motion they were sometimes taken.

Effects of the substances used in these experiments may be summed up as follows: The odor of the iodine solution was not deterrent in any manner; the after-effect seemed to be more disturbing in the mouth region than did that of other substances. Oil of pennyroyal and oil of rose geranium when they touched the lips led to wiping the mouth-parts with the forefeet. No similar effect was noticed from clove oil, cedar oil, and bergamot oil. When bisulphide of carbon was applied to the mealworms, the toads gave some evidence of discomfort, gulping several times in succession after having taken larvae prepared with this substance. Aniline oil did not eause any reactions that seemed to result from stimulation of the mouthparts, nor was it repellent because of its odor.

\section{FOOD AND DARKNESS}

The diurnal retreat of the toad into dimly illuminated places and its habit of feeding in the night are well-known. Frogs on the contrary are most active during the daytime. In connection with the feeding experiments on the toad it was desirable to know what degree of darkness was prohibitive to its finding food. Are other stimuli present, do smell, hearing and touch share in the reactions of seeking food?

\section{Materials}

The same individuals that were used in the previous experiments were used in these trials. The toads appeared to be in normal condition, giving no evidence of having undergone any untoward experiences. No changes were made in the care given the toads. The experimentation was done in a photographic dark-room with controllable illumination.

The experimentation chamber was a box, 30 inches long, 20 inches wide, and 8 inches high. Loam and leaves had been allowed to remain in the box for some days, thus giving the chamber some semblance to the toad's natural habitat. 


\section{Experiments}

To ascertain whether any stimulus other than the optic is called into play in the finding and taking of food the following experiments were performed.

Toad No. 1 was placed in the box, which was empty except for a covering of moist filter paper on the floor, and allowed to remain undisturbed for some time. There was no excited hopping about during this period of illumination. The light having been cut off, the toad crept along the wall, and finally came to rest in a corner where it attempted to burrow as though it were on soil. After two hours of darkness some mealworm larvae were introduced into the box. These were placed centrally on the floor and as these changes were made in darkness the larvae were not seen by the toad. The toad was then lifted from its position in the corner of the box and placed immediately over the glass plate on which the larvae were and facing them. In this position there was no thigmotactic stimulation, as there would have been in the corner position. By listening to the sounds within the box the movements of the toad could be followed. The position of the larvae and the toad were noted at the end of two minutes of darkness. The toad had resumed the corner position, the larvae had moved out and away. from the plate, one of them being within 2 inches of the toad. Two minutes of darkness brought no further movement on the part of the toad. The larvae were distributed around the sides of the box. After another minute of darkness, the light was turned on and at the first visible movement of the mealworms, the toad turned and jumped toward them. There followed no movements on the part of the toad in successive periods of darkness; but each time the box was illuminated the least movement on the part of the mealworms called forth characteristic movements from the toad.

Toad No. 2 was tried with dungworms in a manner similar to that just described for Toad No. 1. No notice was paid to the worms in the dark but in the light the toad followed the 
worm some distance and finally picked it up, using both the tongue and lips to do so.

In another trial, the toad was placed in the center of the floor and the worms were distributed in the portions of the box near the walls. The illumination was lateral, thus leaving one side of the box quite dark. Movement of worms in the darker regions of the box were not seen by the toad, even when it was turned toward the worms. When a worm moved in the light part of the box, the movement soon attracted the attention of the toad and the characteristic reaction followed immediately. Repetition of the experiment several times with other toads gave the same results.

When the dungworms were replaced by pillbugs (Oniscus), these were immediately caught when in the light, but not when in the dark.

Other trials with mealworms, earthworms and dungworms gave like results; only during the periods of illumination was the food sought and then with no discrimination in favor of any particular form.

Other trials, with very dim daylight as a means of illuminating the chamber gave identical results. If the mealworms or the dungworms were in the darker portions of the chamber, they were unnoticed by the toad. When the box was covered so as to cut off all illumination, there were no movements on the part of the toad; darkness prohibiting entirely any food seeking activities.

In the lighted portions of the chamber the worms were only seen if in the direct visual field; if somewhat to the rear or to the side of the toads they apparently could not be seen, except when in very vigorous motions.

\section{Abnormal odors and darkness}

In connection with the darkness experiments, trials were made with the same odorous substances that had been used in the preceding experiments. The same individual toads were used as before. Mealworms were treated with applications of oil of clove, carbon bisulphide, and oil of rose gera- 
nium and wcre allowed to remain in the experimental chamber with the toads under the same light conditions as described in the preceding trials. The presence of the odors did not stimulate the toads to seek or avoid the worms in the dark. Again, as observed in the previous trials, the presence of the odorous substance did not deter the toads from taking food in the light.

\section{ODOR-STREAM EXPERIMENTS}

\section{Apparatus}

From the experiments previously recorded there was no positive evidence that odors were concerned with the taking of food by the toads. Odorous substances when taken into the mouth by accident do not stimulate the receptor organs to the degree of inhibiting the act of deglutition. A possible explanation for this might be sought in the relation of the external nostrils to the mouth. Even if the olfactory function were present to but a slight degree, it might be possible to demonstrate its presence by leading the odors directly to the nasal opening. If the vapors could be brought directly to the epithelial surfaces in appropriate manner, reactions might occur. It seemed desirable to devise some method for doing this.

After some trials, an apparatus of a satisfactory kind was finally devised. An outline of it is shown in figure 1 . The arrangement of the parts is as follows: From the reservoir, $A$, water displaced the air contained in $B$. By means of screw clamps at $x$ and $y$ the rate of flow of the water was controlled. The clamp, $x$, was adjusted for the flow, while clamp $y$ is used for starting and stopping the stream as a whole. $C$ is a small reservoir in which was suspended a vial, $D$, containing the odorous substance used. The distal end of the outlet tube, $b$, was submerged in the material contained in $D$; the air stream carried over and out of $C^{\gamma}$ would consequently be impregnated with the odor to be tested. By means of appropriate connections and the nozzle tube, $d$, three millimeters in diameter and bent in proper form, the air stream was led into the experiment chamber, $E$. Elastic suspension of the tube, $d$, automatically raised the tube 
and allowed freedom of movement. For control tests there was provided a duplicate of the tube, $d$, which could be connected directly with $B$; thus avoiding any possible errors by contamination from the material in $D$. The chamber, $E$, was an open cylinder, the lower end resting in a shallow vessel containing soil easily changed and moistened. To eliminate other dis-

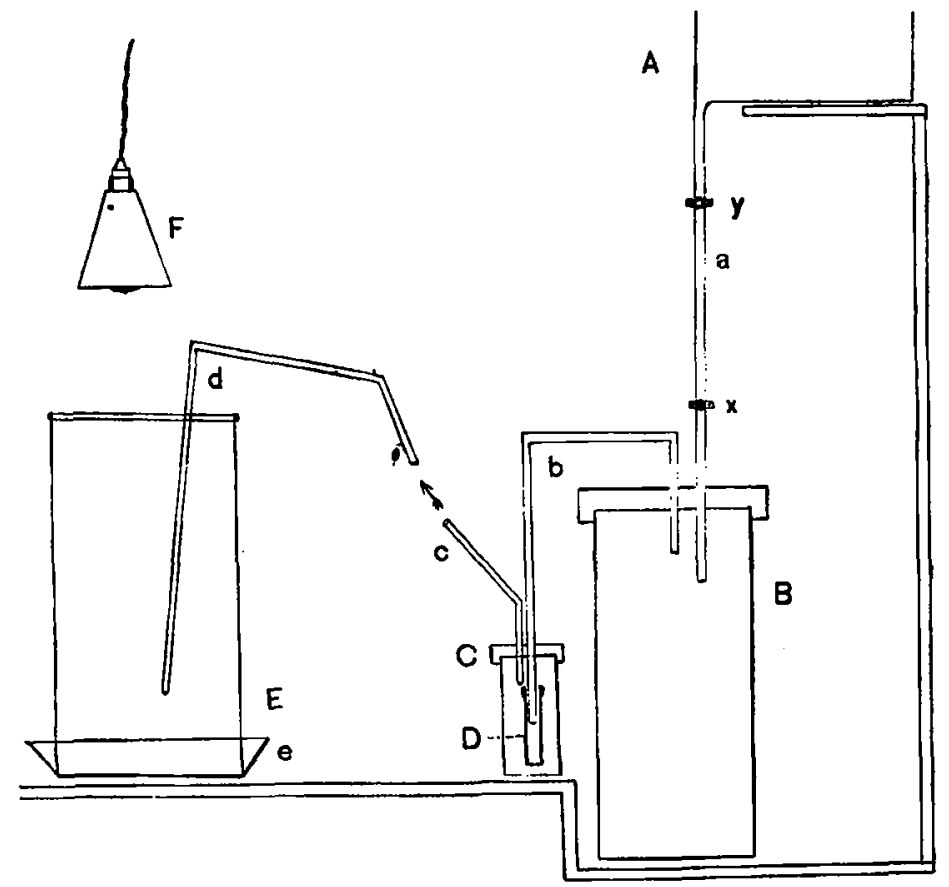

Fig. $1 A$, reservoir; $B$, air chamber; $C$, odor chamber; $D$, vial; $E$, experiment chamber; $F$, lamp; $a$, water tube $A$ to $B ; b$, airtube $B$ to $C$; $c$, outlet tube for odor stream; $d$, nozzle tube for chamber $E$; $e$, vessel containing sand; $x, y$, clamps.

turbing factors the cylinder was covered with black cloth. The illumination of the chamber, $E$, was by an electric lamp of 8 c.p. This was of advantage in orientation, as the toads are positively phototropic (Pearse '10).

The apparatus was arranged near the water supply in a basement room from which daylight could be excluded. Several other chambers similar to $E$ were provided in order to adjust 
the toads to the new conditions. Toads not accustomed to the chamber were at first much disturbed, reacting to various other influences. Attempts to crawl out of the chamber, to bite the end of the tube, $d$, or to be restless within the chamber were some of the reactions noted. After adjustment normal reactions were then exhibited, such as feeding or burrowing into the soil. The apparatus was kept well ventilated between periods of experimentation as well as during the testing periods.

\section{Rate of flow of odor-stream}

The rate of flow of the air stream was made as uniform as possible. If allowed to flow uninterruptedly the 3000 cubic centimeters of air in $B$ were displaced by the water from $A$ in from 80 to 90 minutes. At this rate the flow is approximately 35 cubic centimeters per minute. That such a stream is not sufficiently strong to be perceptible cap be demonstrated by placing the nozzle tube near the moistened lips or the tongue. The flow of the stream could also be judged from the frequency of escaping bubbles when the end of the tube was immersed in water.

The tests as carried out followed a uniform plan consisting of, first, a control test: with air, and secondly, a trial proper with the odor stream.

\section{Methods}

In the control test the toads were first subjected to the air stream coming from $B$. The nozzle tube, $d$, was directed toward various body regions, namely, flank, axillary region, anal region, and surface of the eye (as near as possible without contact). After this test for possible stimulation of integumentary sense organs, the air stream was next directed to the nostril to ascertain if there was any stimulation of the nasal epithelium. The test with the odor stream followed next and the same parts of the body were tested as before.

The toads used in the feeding experiments were used for the tests with the odor stream and were normal in all their activities. 
The one exception was Toad No. 4, which seemed to be in a semi-hibernating condition during the entire period. Two other toads taken in the fall of 1912 were likewise tested with this apparatus. Although no two individuals were identical, the results of the trials agree in all essentials.

\section{Substances used in the tests}

Oil of cloves, oil of pennyroyal, oil of rose geranium, cedar oil, bergamot oil, aniline oil, carbolic acid, olive oil, castor oil, and cod liver oil were used, though some of the substances gave entirely negative results.

Trials were also made with the odor stream from food materials used by the toad. For these tests mealworm larvae, earthworms, dungworms, and cockroaches and other insects were put directly into the chamber, $C$ and the air stream was allowed to carry over any odors that were present. In no case was there evidence of olfactory stimulation from these bodies.

\section{Experiments}

The attempt of Graber ('85) to determine the olfactory reactions in some of the amphibians proved unsatisfactory. Aronsohn ('86) and Gourewitsch ('83) noted the effect of odors on the rate of respiration. The animals, while confined in covered beakers, were exposed to odors of turpentine and equ de cologne with disturbing results.

Early in my own tests it was seen that chloroform, ammonia, ether, turpentine, formol or alcohol when introduced into the chamber were disturbing. Even though the air stream with these substances was not near the nostril, reactions followed very quickly and with the proximity of the stream to the nose the disturbance was increased.

Ammonia, chloroform and turpentine when directed upon the anterior head region induced the toad to jump away from the tube to one side or even out of the chamber. The odor of turpentine resulted in a very characteristic attitude, the head 
being bent down between the forelegs, the body raised from the ground and best described as humpbacked. Ether or alcohol did not produce reactions so decidedly vigorous, though the toads retreated quickly from the tube.

The respiratory movement was retarded by all the substances that stimulated the olfactory end-organ. Tests made with the odor stream when the act of inspiration was suppressed were devoid of any resultant motor activity.

After the earlier tests with ammonia, ether, etc., the essential oils were used and some were found to be more effective in calling forth characteristic reactions than others. Some were entirely negative in effect, as, for instance, castor oil, cod liver oil, and olive oil.

What reactions could be considered as directly called out by the stimulation of the olfactory organ?

When the odor stream from oil of cloves or pennyroyal was allowed to spread over the anterior region of the head and presumably enter into the nasal cavity with the inspired air, the first motor act consisted of a slight bending down of the head, away from the nozzle of the tube, and a cessation of the respiratory movements. If the tube were removed quickly, the toads soon resumed the normal position and the respiration movements went on again with little interruption. If the odor stream was allowed to flow continuously upon the nostrils, respiration was entirely suppressed for some time. Often the toad made motions with the forelegs resembling wiping. When very much stimulated by the stream the animals moved away from the tube. The bending of the head was most noticeable when the toads were partly hidden in the sand. At such times respiration ceased, the head was bent more anteriorly and the animals endeavored to burrow down into the soil. The act of burrowing could be hastened by directing the tube repeatedly at the nostrils during such a test. This position of being partly buried in the soil was most favorable for observation. When thus buried the animals did not move about and the stream could be directed more accurately against the nostrils than at other times when the animals were free to move about. 
The tests were carried out in periods of approximately fiveminute durations, followed by intervals of rest varying in length of time. It sometimes happened that the animals were too restless to allow a fair interpretation of their reactions; in such cases the tests were discontinued. Other individuals again, were amenable to the trials for several hours without showing themselves to be disturbed. Precaution was taken that no odors entered the chamber otherwise than by means of the appropriate tube.

Records of the trials indicated what reaction followed the stimulus applied to the nostrils. The records shown in table 1 will serve as samples.

TABLE 1

Toad No. 1

\begin{tabular}{|c|c|c|}
\hline TIME & strmulus & REACTION \\
\hline 3.00 & air & moved to one side \\
\hline 3.05 & repeated & burrowing normally \\
\hline & toad was allowed to rest fif & en minutes \\
\hline 3.20 & odor of oil of clove & head bent downward \\
\hline & repeated & head bent downward \\
\hline & repeated & wiped with right foot \\
\hline & repeated & moved away to left \\
\hline & repeated immediately & moved away to left \\
\hline 3.25 & $\begin{array}{l}\text { repeated } \\
\text { repeated }\end{array}$ & $\begin{array}{l}\text { wiped; attempted to climb } \\
\text { wiped again }\end{array}$ \\
\hline
\end{tabular}

Toad No. 2

\begin{tabular}{l|l|l}
\hline 10.30 & $\begin{array}{l}\text { air } \\
\text { repeated } \\
\text { repeated } \\
\text { repeated } \\
\text { Toad allowed to rest five } \\
10.35\end{array}$ & $\begin{array}{c}\text { at rest } \\
\text { at rest } \\
\text { at rest } \\
\text { at rest }\end{array}$ \\
$\begin{array}{l}\text { odor of oil of pennyroyal } \\
\text { repeated } \\
\text { repeated immediately } \\
\text { repeated }\end{array}$ & $\begin{array}{l}\text { wiped } \\
\text { head bent downward } \\
\text { head bent downward } \\
\text { moved toward right }\end{array}$ \\
& $\begin{array}{l}\text { repeated } \\
\text { repeated immediately } \\
\text { repeated }\end{array}$ & $\begin{array}{l}\text { head bent downward } \\
\text { head bent downward }\end{array}$ \\
\hline
\end{tabular}


Bergamot and cedar oil resulted in fewer reactions than oil of clove and oil of pennyroyal, showing them to be less stimulating than the other oils.

As already indicated, the stimulus was effective only while inspiration was in progress, for pressure of the stream was so slight that it could not force the odorous particles into the nostrils. The reactions were not characteristic of the different odors. It might be said that the reactions differed in degree, only, since there were only differences of vigor with which the reactions were executed. Even individuals differed in this respect at different times during the trial periods. Other factors such as temperature or tendency to hibernate may have had some influence in this aspect of the reactions. Absolute parity of the tests could of course not be obtained.

The relative effectiveness of the odors in stimulating the receptors was as follows: Most effective and approximately equal were oil of cloves, and oil of pennyroyal; less effective were oil of rose geranium and cedar oil; and least effective, with reactions infrequent, were bergamot oil and carbolic acid.

Odors from castor oil, olive oil, cod liver oil, living mealworms, earthworms, dungworms, cockroaches, decaying meat and decaying leaves in soil were without effect.

\section{Controls and operations}

The controls used in the tests seemed to be confirmatory of the presence of the olfactory function; yet a possibility existed that other receptors had been stimulated at the same time. The ophthalmic branch of the trigeminal nerve supplies the region of the head anterior of the nostrils, with some. fibers possibly present within the nasal capsule. This being so, stimuli coming to this region of the head could call forth reactions easily through this branch as well as through the olfactory organ. To ascertain whether this branch had been stimulated several sets of experiments were tried.

The nostrils were closed by suturing with silk thread. Closing the nostril in this manner was of more serious consequence to the 
toads than to fishes. This established an effective hindrance to the respiratory current, therefore it was found impracticable. If the stitches were not placed deeply, the muscular movements of the nostril soon caused the thread to cut through the margins, Furthermore, complete closure of the nostrils was apparently fatal in several preliminary trials.

Filling the nasal aperture with melted vaseline was only partly successful, entrance to the capsule being prevented by the nostril valves. The vaseline could be "troweled" into the opening. It was evident from the actions of the animals that the vaseline was discomforting. The toads showed decided restlessness and attempted to wipe their heads.

Some tests were made with toads so treated. When both nostrils had been successfully closed, no reactions traceable to odorous substances could be observed. If only one of the nostrils was closed, the odorstream, when directed upon the open nostril, was effective in causing a reaction.

Clove oil and pennyroyal were the substances used in the tests with the nostrils partly or wholly closed, these having been most efficient in calling forth reactions in the normal toads.

To be certain of the assumption that the reactions noticed with the odorstream were called forth by the stimulation of the olfactory receptor, operations of two kinds were performed on the toads.

In one of the operations, the olfactory tract was severed. In the other, it was necessary to section the ophthalmic branch of the fifth nerve. After etherization, the olfactory tracts were severed at the anterior border of the eyeball. The ophthalmic branch of the trigeminal was cut by piercing the integument of the optic capsule at the anterior inner angle of the orbit and cutting across the floor of the orbit. After recovery, only the specimens reacting normally to other stimuli were used for the tests.

Toads in which the olfactory tracts had been severed did not react to the odorstream. If partly buried in the sand, they were undisturbed by odors coming through the tube. The head was not drawn down, nor did they move away from the tube. One 
peculiar action was noted in the toads so tested; when the tream was first directed to the nostrils, they sometimes would gasp, often repeatedly, but without interrupting the respiratory act.

The reactions of the toads in which the olfactory tracts had been severed are well exemplified in the record of Toad No. 1 (table 2).

The reactions of toads in which the ophthalmic branch of the trigeminal nerve has been cut is shown in table 3 .

Since oil of cloves and oil of pennyroyal had given the best reactions in the normal toad these substances were used after the operations. As may be seen from the record above, the operation on the ophthalmic branch of the fifth nerve did not disturb the olfactory function.

Ether and chloroform did not affect the operated toads in any manner different from the normal animals.

After cutting the olfactory tract the animals were apparently less active than toads with the ophthalmic branch severed.

TABLE 2

Toad No. 1

\begin{tabular}{|c|c|c|}
\hline $\operatorname{rim}$ & stmulus & REACTION \\
\hline 1.10 & $\begin{array}{l}\text { odor of oil of clove } \\
\text { repeated often } \\
\text { repeated often } \\
\text { with continuous odorstream }\end{array}$ & $\begin{array}{l}\text { resting } \\
\text { moved forward } \\
\text { wiped once } \\
\text { respiration normal }\end{array}$ \\
\hline Toad & allowed to rest for ten minutes an & chamber well ventilated \\
\hline & $\begin{array}{l}\text { odor of oil of clove } \\
\text { continued for five minutes }\end{array}$ & $\begin{array}{l}\text { gasped at first } \\
\text { wiped once }\end{array}$ \\
\hline & Allowed to rest ten $\mathrm{m}$ & nutes \\
\hline 1.40 & $\begin{array}{l}\text { odor of oil of clove } \\
\text { continuous for four minutes }\end{array}$ & wiped once \\
\hline 1.45 & $\begin{array}{l}\text { further stimulation } \\
\qquad \text { Allowed to rest ten } \mathrm{m}\end{array}$ & gasped once \\
\hline 1.55 & $\begin{array}{l}\text { odor of oil of clove } \\
\text { continuous odorstream } \\
\text { continuous odorstream } \\
\text { Allowed to rest ten m }\end{array}$ & $\begin{array}{l}\text { quiet; respiration sus- } \\
\text { pended } \\
\text { respiration resumed } \\
\text { no reactions } \\
\text { inutes }\end{array}$ \\
\hline $\begin{array}{l}2.10 \\
2.15\end{array}$ & $\begin{array}{l}\text { odor of oil of clove } \\
\text { continuous stream }\end{array}$ & $\begin{array}{l}\text { changed position onee } \\
\text { and respiration normal }\end{array}$ \\
\hline
\end{tabular}


The latter were more responsive to the optic stimulations. The toads with the olfactory tract cut preferred to lie quietly in the sand. The feeding reactions were not inhibited by either operation.

Some toads collected in the late summer of 1912, tested similarly, gave evidence coinciding with the data of the previous tests.

The results of these experiments show that odors stimulate the olfactory receptors, whereby certain motor activities of unquestionable value to the animals are called forth.

TABLE 3

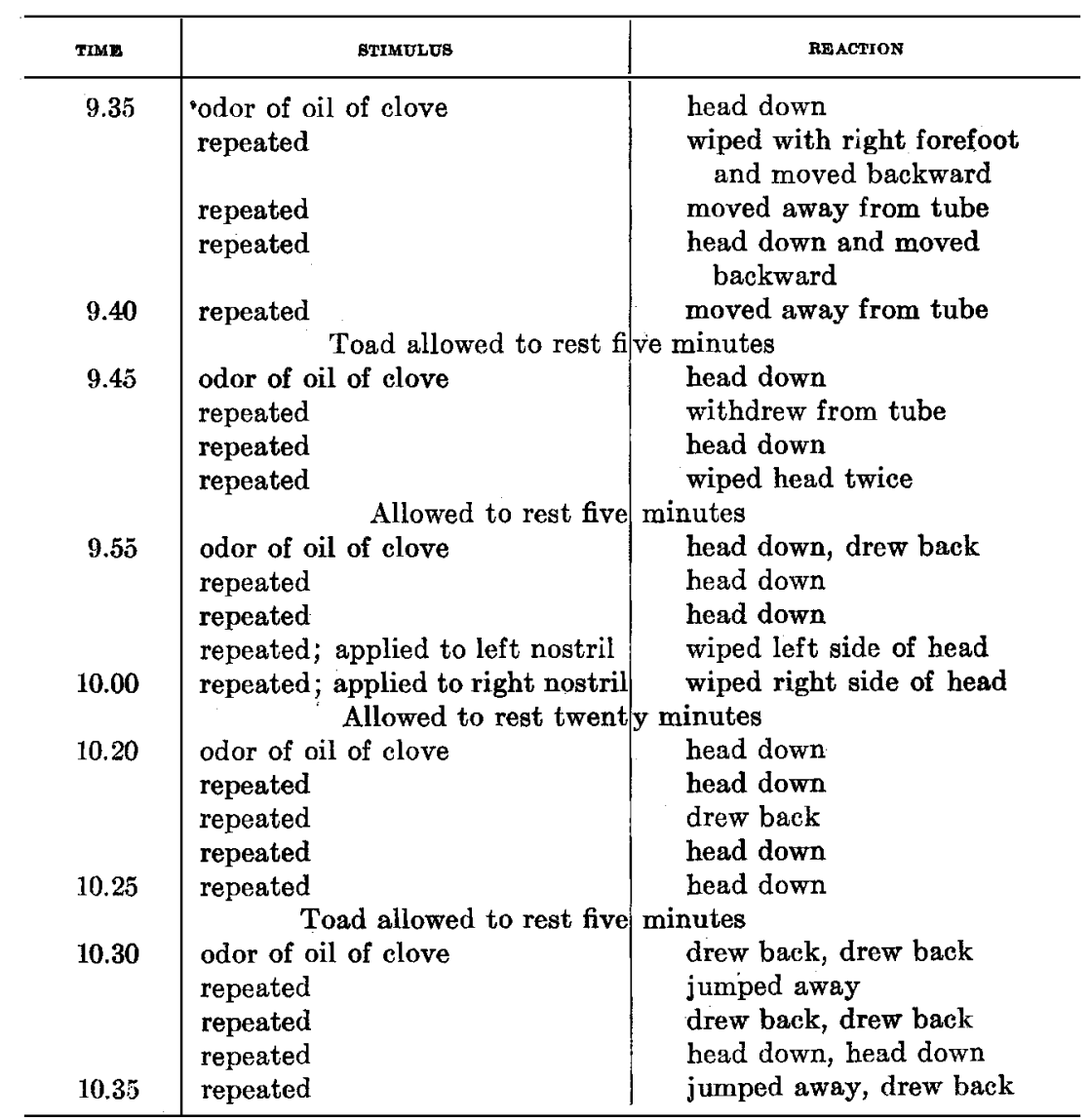




\section{EXPERIMENTS WITH TADPOLES}

\section{General}

Knauer ('75) emphasizes the fact that some of the larval anurans are less phytophagous than is commonly supposed and instances the fondness of toad tadpoles for animal food. Holmes ('07) also states that decomposing insects, earthworms, etc., are acceptable as food to frog tadpoles. That certain European anurans feed indiscriminately like the earthworm is a wellknown fact. Whether vegetable material must not be in the early stages of decomposition before becoming available as food for tadpoles has not yet been determined. It is certain that many unicellular and filamentous algae may be ingested repeatedly before digestion is complete.

Nagel ('94) denied the olfactory function to aquatic vertebrates. His theoretical objections have been refuted for the fishes by the work of Parker ('10; '11), Sheldon ('11), and Copeland ('12). The question still remains open as regards amphibians and its solution depends upon suitable material and methods. This was reason sufficient to attempt an investigation of the olfactory function in the tadpole of the toad. Preliminary trials gave evidence at once that the tadpoles were responsive to the presence of decaying animal matter in their immediate vicinity. Tadpoles placed in a vessel containing filtered water for a day or two, the feces being removed frequently, soon come to be in a state of hunger. Water not filtered contained at all times organic material enough to form a delicate film upon the walls of the vessel. This film of partly decomposing organic matter is a source of food for the tadpoles and must be removed. For like reasons the feces must be taken away.

In the preliminary trials particles of dead earthworms, dead fish or bits of meat undergoing decomposition were placed in the vessel containing the hungry tadpoles Such particles of food were quickly found by the tadpoles.

The feeding trials were performed on tadpoles of three successive years. The first set was obtained at Woods Hole, Massachusetts, on August 10, when the tadpoles were about to 
metamorphose. Some of the larvae had one, others both pairs of appendages well developed, and a few specimens passed through the final phases after having been brought into the laboratory. They were kept in shallow vessels with some of the bottom detritus from their original habitat. Experimentation and natural causes gradually diminished the numbers available for the trials, but the tadpoles appeared to be normal in their activities at all times. The tadpoles surviving through the period of experimentation were killed by accident in the month of January following.

The second set were tadpoles taken in May of the following year in the vicinity of Cambridge. They did not lend themselves well to experimentation. Conditions appeared to be unfavorable for them in the laboratory. Experiments therefore were carried on with but small numbers, but so far as these went they were corroborative of those from the first set.

The tadpoles included in the third set, were taken in June, 1913, from two different localities: namely, Cambridge and Woods Hole, Massachusetts. The tadpoles were experimented with particularly to show that the olfactory reactions might be completely checked by a certain procedure and then revived.

\section{Methods}

The method of procedure in the trials was as follows: The tadpoles were placed in filtered water for twenty-four to fortyeight hours before experimentation began. Then the food was introduced into the vessel; the reactions being noted in accordance with the shifting of the food placed in the vessel.

Food used in the tests consisted of particles of fish, earthworm, or meat in decomposition. At first the food without any envelope was placed free in the vessel, but later it was wrapped in cloth. In other trials again, two packets were placed in the water; one containing the food, the other without it.

Very little difficulty was experienced in noting the reactions of the tadpoles. When the two packets were presented, the tadpoles distinguished quickly the one containing the food. 
When confined to shallow vessels, the actions of the tadpoles of the toad and of the frog of approximately the same stage, were somewhat different. In general, the frog tadpoles swim along the vessel walls. The toad tadpoles, on the other hand, move in all directions over the bottom or near the upper surface of the water.

When toad tadpoles came into the vicinity of the food, either covered or open, the reactions seemed to indicate stimulation of some kind. They swam from side to side, and often when near the food would turn directly to it. When the food was found the tadpoles attacked it very eagerly. When two packets had been introduced the tadpoles did not remain upon the packet without food nor did they nibble it as they did the one containing food.

\section{Experiments}

a. First set of tadpoles. The records of several of the trials are here given in detail:

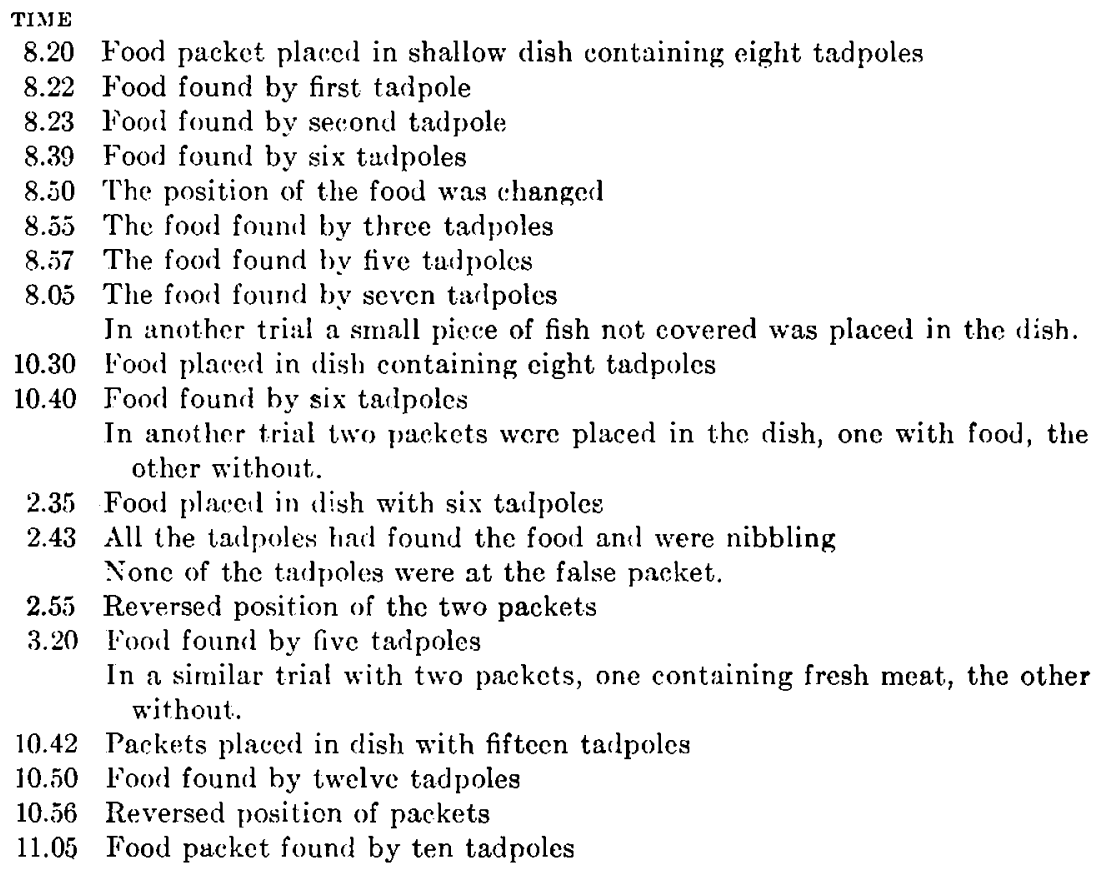


The totals of the trials carried on with the larva of the first set gave these results: In 160 trials, food packet was found 120 times. Trials carried on from time to time up to the accidental loss of the tadpoles resulted in similar ratios.

$b$. Second sel of tadpoles. The conditions were unfavorable for keeping these tadpoles and because of this circumstance only a small number of individuals were available. The trials were carried out in a manner similar to those for the first set.

It needs only be said that the results were similar to those obtained from the experiments of the first set. Precautions were taken with this set to have the two packets identical in appearance, and to transpose them in position. To avoid the accidental finding of the packets as much as possible, they were placed some distance from the sides of the vessel. The toad tadpoles swam more rapidly than the frog tadpoles, and were also more erratic in their movement in the water. It could be easily determined whether they were influenced by the presence of the food mass near them. In a few cases only did there seem to be a visual stimu us influencing the tadpoles to react; such being occasioned by the very lively actions of other tadpoles already at work on the food mass.

c. Third set of tadpoles. For the purpose of verifying the results of the previous experiments, similar experiments were performed with the tadpoles of the third set in June and July of the third season. As stated, these tadpoles were obtained from two different localities and kept successfully in the laboratory, metamorphosis being deferred for the time being. The tadpoles were unquestionably those of Bufo americanus, having been obtained earlier than the time when the mating call of Fowler's toad was heard.

The food used in these experiments was dead and partly decomposed frog tadpoles, earthworms, and beef liver. These materials were either placed freely in the vessel or covered with cheesecloth one or two layers in thickness. In a similar way, as previously described, two packets were used in some of the trials; one containing the food, the other being identical in appearance but without food. 
A number of trials in which the food was placed in the vessel with the tadpoles showed that the reactions of the tadpoles depended somewhat on the size of the vessel. In a small vessel the time necessary for the food to be found by a certain number of the tadpeles was usually less than in a larger vessel. The same is true if the food is placed near the side of the vessel, say within an inch of the side wall; in such a case the animal swimming through the zone impregnated by the odor is influenced more quickly than when the food is centrally placed.

In the trials with two packets discrimination was very evident in the actions of the tadpoles. In the beginning of the trial the reactions were at all times apparently without choice. After the packets had been allowed to remain in the water for a short time, the tadpoles always endeavored to feed from the packet containing the food. Even if the tadpoles rested on the 'dummy' packet very little attempt was made to nibble. Transposition of the two packets was accompanied by a corresponding redistribution of the tadpoles.

This last method was modified several times, by exchanging the envelopes of the packets, or by substituting an envelope saturated with the odor of the food material for the food itself. When this was done, the tadpoles congregated upon the foodsaturated envelope, finding it as they did the food open in the water, or when contained in the envelope and allowed to remain for some time.

An attempt was made to determine whether the tadpoles would orient themselves to an odor-saturated waterstream which was allowed to flow into a vessel containing them; but this experiment was fruitless of results, although there was some slight evidence that the current was especially stimulating.

Corroborative of the earlier findings of the experiments on the two previous sets, experiments carried out with the third set were of greater value in this study in what may be called operative tests.

To determine whether the reactions of the toad tadpoles as already described are due solely to the stimulus received 
by the olfactory organ, attempts were made to inhibit such stimulation in various ways. This was found to be rather difficult and in the light of the earlier attempts the evidence was not very convincing. The diminutive size of the tadpoles is the principal factor militating against successful operations.

Cutting the olfactory tract is the method by which inhibition may be made absolutely certain. In this method the chief difficulty lies in determining the proper degree of anesthetization for the operation and subsequent revival of the animal. Chloretone of 0.1 per cent was used for this purpose, as the tadpoles could be brought into a vessel with fresh water and revived. After being anesthetized the tadpoles were bedded in a bit of absorbent cotton held in the hand, and with a needle the cranial case was pierced in the median line anterior to eyes. The shock attendant upon the operation or the manipulation was disastrous in most cases, and only a few specimens survived. Within a few days these tadpoles became less vigorous, and finally all succumbed.

The few individuals so operated upon and tested for reactions resulting from stimulation to the olfactory sense organ did not give sufficient evidence from which satisfactory conclusions could be drawn.

In another manner the inhibition of the stimulation and the reactions was also attempted. The external nares of the toad tadpole are comparatively large and it was possible to fill the nares with white vaseline, the tadpoles being bedded in moist absorbent cotton. Tadpoles so treated showed the presence of the vaseline to be disturbing in effect. The plugs prevent the respiratory stream from entering the nasal openings, the swimming movements are not so vigorous as under normal conditions, the chief endeavor of the tadpole being to free itself from the disturbing material. The temperature of the water is to be taken into account here, as the vaseline could be removed quite readily by placing the tadpoles in water slightly warmed. As soon as the vaseline has been dissolved the tadpoles again act in normal manner. This method of treatment was made use of in the first 
and second sets, but on account of the comparatively small numbers at hand, the results could not be considered as conclusive.

With the material of the third set the chief aim was to determine whether the presence of the vaseline plugs was beyond doubt inhibitive of the apparent olfactory reactions. Some operations of cutting the tract were carried out, but the after effects were in most cases disastrous to the tadpoles, and therefore special stress was placed on plugging the nasal openings.

Making use of the same individual tadpoles in the successive trials, these groups were isolated in filtered water for some time previous to each trial, and tested repeatedly for reactions to the food as presented (without an envelope) while the nasal openings were in normal condition, or when filled with the vaseline plug.

The trials with the tadpoles in this series were carried out in the following manner: The tadpoles were isolated in filtered water for at least twenty-four hours, in a few cases forty-eight hours, but not beyond this, as the tadpoles showed that a longer period without food was disastrous to them. After isolation for the designated length of time, the tadpoles were tested for the presence of food in the water; immediately after this the nasal plugs were put in, and the tadpoles transferred to a vessel free of food or vaseline. The food was then introduced. Unless the food mass was placed immediately in the proximity to the tadpoles they exhibited no such activities as they previously had. When swimming and moving about in the vessel, there were no such positive attempts to find the food as when normal. The trials were repeated several times with different groups of individuals, in each case allowing several days to intervene between the trals, the tadpoles being provided with food and water from the stock.

The tadpoles showed no bad effects from the plugs of vaseline in the nasal openings, reacting freely in the later trials as well as in the earlier experiments.

Tests made with the tadpoles having the plugs in the nares showed them unable to discriminate between two packets one of which contained food, while previous to the plugging definite choice had been made by them in favor of the food packet. 
The conclusion reached from these experiments as described for the different broods of tadpoles is that the presence of the nasal plug is effect ve in inhibiting any stimulus coming to the sense organ and consequently no corresponding reaction follows.

\section{DISCUSSION}

\section{Toads}

In its method of obtaining food the toad seems to respond to the visual stimulus entirely. This stimulus is apparently effective only when it involves motion. It is not always followed by perfect reaction, for substances inappropriate as food are often taken accidentally. Rejection of such material occurs in compliance with mechanical or tactile stimulation.

Nor does the gustatory function appear to be of any importance in feeding. Gaupp ('04) does not consider the function of the epithelial endplates of the mouth cavity to be established. $\mathrm{He}$ refers to Bethe as bringing forward the best evidence favoring them as tactile organs. It has been shown that strong solutions of picric or acetic acid applied to the epithelium of the mouth cavity will cause appropriate motor activity. Such reactions take place without reference to the point of application of the acid, whether this be in regions supplied with endplates or devoid of them. The latent period between stimulus and reaction is of appreciable duration.

These considerations speak against the belief that these organs are gustatory in function.

Until the contrary is proven, the similarity of food materials of frogs and toads argue for similarity in structure of the epithelium of the mouth. Observations and feeding experiments tend to confirm this view. Food does not remain in the mouth cavity any great length of time.' Deglutition follows almost instantly, and therefore the sense of taste would be of minor importance. Under certain conditions regurgitation may occur. If substances disagreeable to taste are taken into the mouth the animals might be expected to resort to this expediency more often. 
In no case in the course of the feeding experiments was cognizance taken of the unusual substances coming into the mouth to the degree that food was ejected or regurgitated. The experience cited by Knauer ('75) of toads refusing decomposing earthworms is probably referable to tactile stimulation. The nature of the organisms serving as food for the toads under natural conditions is such, that materials differing in texture markedly from the normal might be sufficient to cause refusal.

To establish any connection between food used by toads and the possible odors inherent to the food seems difficult at present. Although evidence is negative, this is qualified by the fact that the data are really not sufficient to establish any conclusion on this question. Natural foods are apparently taken indiscriminately. Stimulation of the receptors may take place; the presence of such stimulation and the effect are not yet demonstrable.

Our inability to recognize the quality of particular motor reactions following certain stimulations does not argue against the absence or refinement of reactions.

The experiments of Graber ('85) were such as to allow no great value to be attached to them. The unmodified methods used for forms differing so greatly in phylogenetic position and in habit with the very doubtful reactions as recorded, speak against the acceptance of his data as important.

To a similar degree the experiments of Aronsohn ('86) on odors and respiration are of little value in indicating the use of the olfactory organ in anurans. His experiment does not preclude stimulation of the trigeminal nerve. His choice of substances and the manner of experimentation favor the possibility that the fifth nerve is involved. The instance mentioned by Conradi ('01) has not had confirmation of any kind. In the experiments described, the presence of abnormal odorbearing substances has not given origin to stimulation sufficiently strong to inhibit the desire for food.

In all experiments carried out with the lower animals and their reactions toward solutions or vapors there exists the possibility that solutions or vapors are more dilute than was in- 
tended. Whether stimulation is to take place in air or water, it is extremely difficult to work with solutions or gases absolutely standardized. The results of the experiments as conducted show that odors. when in relation with food are not sufficiently deterrent in action to compel the toad to refuse such food. Odors of natural surroundings may stimulate the toads to certain reactions. At present there is no evidence that odors of soil or water are effective in any degree on the olfactory organ of the toad.

\section{Tadpoles}

In contrast with the tadpoles of the frog, the toad tadpole may be claimed to possess an olfactory sense, and possibly to a much greater degree than might be supposed. Anatomically considered the two species appear similar. Differences make themselves evident in a closer study of certain parts. The nasal openings in the toad tadpole are relatively larger than in the frog tadpole. The water stream into the nasal passage of the toad tadpole is therefore of greater magnitude than in the frog tadpole.

Contrary to Exner ('78), as quoted by Gaupp ('04), the nasal openings in both species serve for the incurrent water stream. If to this stream are added other substances: dilute solutions of methylene blue or particles of carmine, the toad tadpoles are very quick to respond to the stimulus. Such substances added to the water current flowing into the nasal chamber of the tadpoles of the frog (Rana virescens and $R$. catesbiana) produce similar reactions. Toad tadpoles react at the immediate entrance of the first substances into the nostril; tadpoles of the frog will permit the stream to flow into the nose for a long period, reacting much more slowly to the stimulus. Probably there is a mechanical stimulus from the carmine which sets free the response.

It is more than probable that toad tadpoles recognize certain foods and their odors. When given the choice as between decaying animal matter and decaying plant substances the former is preferred. 
In the series of tests there was always positive reaction in the presence of the animal food when opportunity for such choice was given. Organs of taste have not been demonstrated in the mouth of the tadpole.

On the other hand, the differentiation of the nasal epithelium into the characteristic olfactory organs and the supporting structures takes place very early and we may safely assume the reactions noted to be the result of stimulation of the olfactory receptors.

\section{Conclusion}

The anurans have been called microsmatic animals; such distinction being based on histological and anatomical comparison with the animals classed as macrosmatic.

The nasal organ of the Anura is a common respiratory and olfactory organ, and in this respect conforms to the organ possessed by the higher vertebrates.

A chambered nasal cavity of considerable magnitude supplied extensively with olfactory epithelium and adequate connections with the central nervous system, predicate functional activity of the sense organ.

The life habits and the phylogenetic position of the anurans suggest that such functional activity not only be present but adequately developed. The presence of receptor organs identical in structure with those found in the higher vertebrates further postulates that functions peculiar to these structures be identical.

The receptor peculiar to the olfactory organ of all vertebrates consists of a neurone whose cell body is peripheral in position. The distal portion of the neurone is characterized by the protoplasmic processes projecting above the level of the surrounding cells, while the proximal end is attenuated and gives rise to one of the fibers of the olfactory nerve. This type of receptor is directly comparable structurally with neurone cells found in the epidermis of many invertebrates (Parker '12). Neurones such as these, found in some of the invertebrates are distinct portions of the receptor-effector system and have been demonstrated as extremely sensitive to chemical stimuli. That 
such receptors, olfactory in function and responding only to stimuli when the cell surfaces are dry were peculiar only to air breathing animals was the earlier assumption.

The work of Aronsohn ('86) and Veress ('03) has shown that in man and the higher vertebrates the olfactory epithelium is bathed by glandular secretions and whatever stimulus reaches the receptor must do so in the form of solutions.

More recently Baglioni ('09), Parker ('10;11), Sheldon ('11) and Copeland ('12) have demonstrated in aquatic animals the stimuli inducing certain reactions to be identical with those noted in the air-breathing animals.

If this assumption is valid, as it appears to be, that the olfactory receptor is the simplest and least differentiated of receptor neurones and stimulated by extremely dilute solutions, we should find the olfactory organ in Anura readily stimulated.

That well defined and characteristic motor reactions have not yet been recognized as results due to stimuli varying in quality may be due to lack of observational data and methods of experiment.

\section{SUMMARY}

1. There is no evidence that toads react to olfactory stimuli pertaining to soil, water, etc.

2. The character of the food is not differentiated by attendant odors to the degree that the adult toad thus distinguishes it.

3. Substances of unusual character and odors, when associated with food, do not stimulate the olfactory organs in such a manner as to bring the toad to refuse the food.

4. The presence of such substances in close proximity to the toad, and invisible because of darkness are not repellent in effect on the toad.

5. Odorstreams specific in character, made to flow over and into the nasal openings stimulate the olfactory sense-organ; such stimulation causing definite motor activities to follow.

6. Appropriate operations are confirmatory that the stimulation by such odorstream is olfactory. Section of the olfactory tract inhibits the reactions. Olfactory stimulation and reactions are 
not affected by section of the ophthalmic branch of the trigeminal nerve.

7. Under circumstances allowing discrimination, the tadpoles of the toad prefer animal foods.

8. Such discrimination appears to rest upon the appropriate stimulation of the olfactory receptor.

9. Tadpoles of the toad show by proper reactions that animal food is recognized, although not visually perceptible.

10. The receptor organ so stimulated must be a distance receptor and thus is olfactory in function.

11. In the metamorphosed toad the visual stimulus is the principal and guiding factor in procuring food. Therefore, it is inhibitory in relation to other stimuli and their resultant reactions.

Postscript. Since the preparation of this paper, Copeland has published in The Journal of Animal Behavior, vol. 3, pp. 260 to 273 , an account of the olfactory reactions of the newt Diemyctylus and has shown that this amphibian can scent food under water as a fish does. 


\section{BIBLIOGRAPHY}

Aronsons, E. 1886 Experimentelle Untersuchungen zur Physiologie des Geruchs. Arch. für Anat. und Physiol., Physiol. Abth. Jahrg. 1886, pp. 321-357.

Baglioni, S. 1909 Contributions expérimentales à la physiologie du sens olfactif et du sens tactile des animaux marins. Arch. Ital. Biol., tome 52, pp. 225-230.

Conradr, A. F. 1901 Toads killed by squash-bugs. Science, new ser., vol. 14, p. 816-817.

Copeland, M. 1912 The olfactory reactions of the puffer or swellfish, Spheroides maculatus (Bloch and Schneider). Jour. Exp. Zool., vol. 12, pp. 363-368.

Exner, S. 1878 Fortgesetzte Studien ueber die Endigungsweise des Geruchsnerven. Dritte Abhandlung. Sitzungsber. d. k. Ak. d. Wissensch. Math.-nat. Cl., Bd. 76, Abth. 3, pp. 171-221, Taf. 1-2. .

Fiscren-Sigwart, H. 1897 Biologische Beobachtungen an unsern Amphibien. Vierteljahrschr. d. Naturf. Gesellsch. Zürich, Jahrg., 42, pp. 238-316.

Garman, H. 1892 A synopsis of the reptiles and amphibians of Illinois. Bull. Ill. State Lab. Nat. Fist., vol. 3, pp. 215-389.

GAUPP, E. 1904 A. Ecker's und R. Wiedersheim's Anatomie des Frosches. Dritte Abt., ix +961 pp.

Gotrewirsch, A. 1883 Ueber die Beziehung des Nervus Olfactorius zu den Athembewegungen. Dissertation. Bern, 8vo, $18 \mathrm{pp}$.

Graber, V. 1885 Vergleichende Grundversuche ueber die Wirkung und die Aufnahmestellen chemischer Reize bei den Tieren. Biolog. Centralbl., Bd. 5, pp. 385-398, 449-459, 483-489.

Hantman, F. A. 1906 Food habits of Kansas lizards and batrachians. Trans. Kansas Acad. Science, vol. 20, part 2, pp. 225-229.

Hrlt, T. 1873 Note on Bufo americanus. Proceed. Amer. Assoc. Adv. Sci., 22nd meeting, part 2, pp. 23-24.

Hodge, C. F. 1898 The common toad. Nature Study Leaflet. Biology Series, No. 1. Worcester, $8 \mathrm{vo}, 15 \mathrm{pp}$.

Holmes, S. J. 1907 The biology of the frog. 2nd Ed. New York, 8vo, ix+ $370 \mathrm{pp}$.

KNAJER, F. K. 1875 Beobachtungen an Reptilien und Amphibien in der Gefangenschaft. Wien, $8 \mathrm{vo}, 57 \mathrm{pp}$.

Lockwood, S. 1883 Bufo americanus at play. Amer. Nat., vol. 17, pp. 683-684.

NAGEL, W. A. 1894 Vergleichend physiologische und anatomische Untersuchungen ueber den Geruchs-und Geschmackssinn und ihre Organe. Bibliotheca Zoolog., Bd. 7, Heft 18, viii +207 pp, 7 Taf. 
NhedHam, J. 1905 May flies and midges of New York. Bull. N. Y. State Mus., No. 86,352 pp., 37 pls.

PARker, G. H. 1910 Olfactory reactions in fishes. Jour. Exp. Zool., vol. 8, pp. 535-542.

1911 The olfactory reactions of the common killifish, Fundulus heteroclitus (Linn.). Jour. Exp. Zool., vol. 10, pp. 1-5.

1912 The relations of smell, taste, and the common chemical sense in vertebrates. Jour. Acad. Nat. Sci., Philadelphia, vol. 15, Second Series, pp. 221-234.

Prarse, A. S. 1910 The reactions of amphibians to light. Proceed. Amer. Acad. Arts and Sci., vol. 45, pp. 161-208.

Quaintance, A. L., ANd Brues, C. T. 1905 The cotton bollworm. U. S. Dept. Agriculture, Bureau of Entomology, Bull. No. 50, 155 pp.

ScraffFrer, A. A. 1911 Habit formation in frogs. Jour. Animal Behavior, vol. 1, pp. 309-335.

Sheldon, R. E. 1911 The sense of smell in selachians. Jour. Exp. Zool., vol. 10, pp. 51-62.

SLonaker, J. R. 1900 Some observations on the daily habits of the toad (Bufo lentiginosus). Indiana Acad. Sci., pp. 167-170.

VERsss, E. 1903 Ueber die Reizung des Riechorgans durch directe Einwirkung riechender Flüssigkeiten. Arch. ges. Physiol., Bd. 95, pp. 363-408. 